\title{
Quantifying Protein Interface Footprinting by Hydroxyl Radical Oxidation and Molecular Dynamics Simulation: Application to Galectin-1
}

\author{
Olga Charvátová, ${ }^{a}$ B. Lachele Foley, ${ }^{a}$ Marshall W. Bern, ${ }^{\text {b }}$ \\ Joshua S. Sharp, ${ }^{a}$ Ron Orlando, ${ }^{a}$ and Robert J. Woods ${ }^{a}$ \\ ${ }^{a}$ Complex Carbohydrate Research Center, University of Georgia, Athens, Georgia, USA \\ b Palo Alto Research Center, Palo Alto, California, USA
}

\begin{abstract}
Biomolecular@urface@napping@nethods@ffer@n@mportant@lternative@nethod@or@haracterizing@protein-protein@nd@rotein-ligand@nteractions@n@ases@n@wich@t@s@ot@ossible@o determine@high-resolution@hree-dimensional@3D)@tructures@f@omplexes.@Hydroxyl@adical footprinting@ffers@@ignificant@dvance@n@footprint@esolution@ompared@with@raditional chemical@erivatization.@Here@ve@resent@esults@f@ootprinting@erformed@with@hydroxyl radicals@generated@on@the@nanosecond@ime@scaleCby@laser-induced@photodissociation@of hydrogen@eroxide.@We@pplied@his@merging@method@o@@arbohydrate-binding@protein, galectin-1.(Since@alectin-1@ccurs@s@థhomodimer, $\$$ ootprinting@ras@mployed@o@haracterize the@nterface@@he@nonomeric@ubunits.@fficient@nalysis@f@he@nass@pectrometry@ata@or the@oxidized@protein@was@achieved@with@the@recently@developed@ByOnic@(Palo@Alto,@CA)

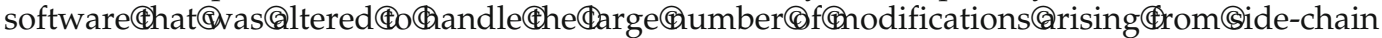
oxidation.@uantification@f@heđevel@f@xidation@has@een@chieved@y@mploying@pectral intensities@or@ll@f@he@bserved@xidation@tates@n@Qper-residueゆasis.đhe@evel@f@ccuracy achievable@rom@pectral@ntensities@vas@etermined@y@xamination@f@ixtures@f@ynthetic peptides@elated@o@hose@resent@fter@xidation@nd@ryptic@igestion@falectin-1.@A@irect relationship@etween@ide-chain@olvent@ccessibility@nd@evel@f@xidation@merged,@which enabled@he@rediction@f@he@evel@f@xidation@iven@heCBD@tructure@f@he@rotein.CThe precision@f@his@elationship@ras@nhanced@hrough@he@se@f@verage@olvent@ccessibilities

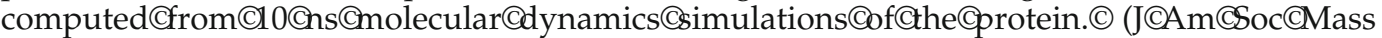
Spectrom(2008,@9,@692-1705)@(2008@American@ociety@or@Mass@pectrometry
\end{abstract}

$\mathrm{T}$

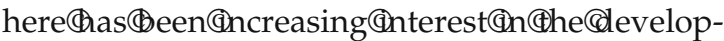
ment@f@high-throughput@nethods@or@haracterizing@protein-ligand@ontact@urfaces@footprinting).(C) One(C) approach@employs@ hydrogen-deuterium exchange@mass@spectrometry@(H/D-Ex@MS)@[1-5]@to

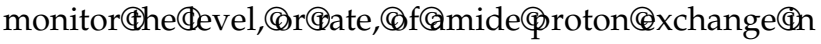
the@ackbone@f@protein@ineuterated@rater.థo@etect and@uantify@he@evel@f@euterium@ncorporation@y mass@pectrometry@ypically@ecessitates@roteolytic@igestion@nder@onditions $₫$ hat@ttenuate $₫$ hdrogen $₫$ ackexchange,@uch@s@ow@H@nd@ow@emperature.đHowever,@nder@hese@onditions,@omplete@igestion@f(†he protein@s@difficult@o@chieve@6].CAdditionally,@while deuterium@xchange@s@ltered@n@he@resence@r@bsence@ofCaigand, Git@is@a@complex@phenomenon@that depends@eavily@n@roteinđolding@kinetics@and@ocal amino@cid@equence.đt@s@lso@vorth@oting@hat@he backbone@mide@rotons@re@not@necessarily@ifferentially@hielded@y@he@resence@f@đigand, $\oplus$ hat $@ s, \oplus h e y$ may@e@hielded@y@ide@hains@in@oth@heđree@nd

Address reprint requests to Dr. R. J. Woods, Complex Carbohydrate Research Center, University of Georgia, 315 Riverbend Rd., Athens, GA 30602,@SA.@-mail:@woods@ccr.uga.edu
bound@form@of@a@protein-ligand@complex.@Chemical derivatization@methods,@uch@s@iotinylation@7,@]@r acetylation $\Phi 9, ₫ 0], @$ which $\$$ ocus@nథhe@ide@hains, $₫$ ave been@employedCto@probe@protein-protein, Cprotein-ligand,@r@rotein-nucleic@cid@nteractions. CThe@dvantage@f(hese@nethods@ver@euterium-exchange@s@hat the@modification@is@irreversible,@facilitating@analysis,

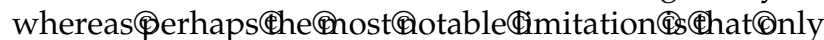
aథew@esidues@r@ypes@f@esidues@ill@eథabeled@n@ny protein.CThus, @he@esolution@f@he@ontact@urface@s extremely@ow.CAn@alternative@hemical@erivatization method@hat@mploys@ydroxyl@adicals@o@xidize@he side@hains@ppears@o@ffer@everal@dvantages.đFirst, hydroxyl@radicals@are@highly@reactive@and@result@in covalent@nodifications $₫$ hat $₫ a$ cilitate@@igh@hroughput proteomic@type@analysis@of@the@product.@Further,@in contrast to H/D exchange, the extent of hydroxyl radical oxidation for any given amino acid appears to depend directly on solvent accessibility [11-13]. Thus, this type of labeling should be useful in identifying ligand contact regions. Lastly, in contrast to other chemical derivatization methods, depending on the manner in which they are generated, and on exposure times, hydroxyl radicals, can react with all amino acid 
side chains. Methods to generate hydroxyl radicals, in biological environments, include direct synchrotron radiolysis of water [14-17], photodissociation of dilute hydrogen peroxide induced by high-energy laser [18-20], UV [13, 21], or $\gamma$-irradiation [22]. Alternative methods include Fenton chemistry [23-25], whereby hydroxyl radicals are generated by contact between hydrogen peroxide and metal-bound ethylenediaminetetraacetic acid, or by high voltage discharge within an electrospray ion source [26, 27]. In several methods, a major drawback is the availability or complexity of the instrumentation. While Fenton chemistry is an affordable method that has been utilized in the structural analysis of nucleic acids [28-30] and has been also applied to study proteins [31, 32], it also requires long incubation times and chemical additives. For a weak interaction, as is typical for many carbohydrate-protein complexes, a long incubation or exposure time would allow the ligand to undergo multiple exchanges with the protein surface, during which the contact region would be exposed to reactive radicals. Additionally, rapid reaction is necessary to ensure that the oxidation of the amino acids takes place before any unfolding or other conformational changes of the protein occurs. To minimize these issues, we believe pulsed laser-induced dissociation of hydrogen peroxide is advantageous due to the relatively rapid speed of hydroxyl radical generation.

Previous studies by Hambly and Gross [19, 20] and Aye et al. [18] have demonstrated the utility of generating hydroxyl radicals by a single laser pulse of dilute hydrogen peroxide. The radical concentration achieved from a single pulse of a dilute peroxide solution $(1 \%$ or less) is adequate to achieve significant levels of protein surface oxidation $[18,19]$. This is an important observation since the resulting oxidation leads to protein denaturation [18] and, thus, although subsequent irradiation would ensure high oxidation levels, it would not be appropriate for 3D structural studies. In the limit, multiple laser pulses can also lead to backbone cleavage [33].

High-resolution footprinting necessitates not only the identification of the sites of oxidation (on a peramino acid residue basis), but also the quantitation of the level or rate of oxidation at each site. Mass spectrometry provides a powerful tool for this characterization although, since the majority of side chains can exhibit multiple oxidation states, data analysis is challenging. In a typical protein sequencing analysis, the protein is digested by a specific protease, such as trypsin, and the resulting fragments sequenced by tandem MS methods. This approach relies heavily on knowledge of the masses of each amino acid and any post-translation modifications. Commonly used proteomics software, such as SEQUEST [34] or Mascot [35], are not optimized to handle the extensive number of permutations generated by the range of possible sidechain oxidation states. To address this issue, we employed a program (ByOnic [36]), which has been spe- cifically modified to handle the large number of amino acid modifications associated with hydroxyl radical oxidation. ByOnic combines de novo sequencing and database searching to match the peptide fragments to a sequence provided by the user.

Although relative peptide abundances in a protein digest may be estimated by spectral counting, the quantitation of proteomics data benefits from more sophisticated treatments [37]. Here we employ a labelfree approach to quantify the subtle differences in pre-residue oxidation levels arising from reaction with hydroxyl radical. Proteolysis of an oxidized protein leads to multiple instances of peptides with the same sequence, which differs only in the extent of oxidation. To quantify the level of oxidation at any given site requires the identification of all peptides with oxidation at that site, using tandem MS. We compute the percentage of oxidation at each amino acid $\left(\% \mathrm{AA}_{o x}\right)$ from the LC-MS signal intensities of each peptide containing a specific oxidized amino acid $\left(\mathrm{I}_{o x}\right)$, relative to the total of all intensities associated with that peptide sequence $\left(\mathrm{I}_{o x}+\mathrm{I}_{\text {non-ox }}\right)$ using the following straightforward relationship:

$$
\% A A_{o x}=\frac{\sum I_{o x}}{\sum I_{o x}+\sum I_{n o n-o x}} * 100
$$

To ascertain the suitability of our use of spectral intensities for quantitation of oxidation levels, as well as to indicate the extent to which a quantitative relationship exists between oxidation and side-chain solvent accessibility, we have applied hydroxyl radical footprinting to a small globular protein for which extensive $X$-ray structural data exists. Galectin- 1 is a homodimer member of the galectin family found in many animals including humans, which has the ability to bind oligosaccharide ligands containing galactosyl residues [38-42]. Galectins are the target of many studies because of their involvement in various biological processes such as cell adhesion, differentiation, regulation of cell growth, regulation of apoptosis, cell activation, mRNA splicing, inflammation, and induction of $\mathrm{Ca} 2+$ dependent signal transduction pathways [43-46]. Due to its small size, and the availability of X-ray structures from various species, with various ligands, galectin- 1 is a suitable protein for mass spectrometric analysis and surface mapping method development.

The interpretation of hydroxyl radical surface mapping data, in terms of 3D structural properties, is based on the assumption that those residues that are exposed to solvent will react more readily with hydroxyl radicals than buried or otherwise shielded residues. To assist in the analysis of the MS data, we have employed molecular dynamics (MD) simulations to predict the time-averaged solvent accessible surface area $(<$ SASA $>$ ) of each side chain [5]. In contrast to X-ray structural data, MD simulations enable the generation of a realistic ensemble of side-chain orientations in solution at experimental temperature, which can be 
particularly important when employing homology models [47]. Additionally, MD refined side-chain ensembles have been shown to lead to better correlation with experimentally-determined levels of oxidation [5], and so provide a robust basis for estimating $<$ SASA $>$ values. This computational approach also allows us to separate the galectin- 1 homodimer into its two subunits and predict the solvent accessibility of the residues in the interface region. In addition, molecular modeling techniques [48-50] can be particularly useful in generating the $3 \mathrm{D}$ fold of proteins of interest when no experimentally-derived structure is available, and in this study we examine the extent to which a homologybased model of galectin-1 can be used to interpret oxidative footprinting data. In principle, oxidative surface mapping could provide a valuable alternative to NMR or X-ray analysis for validating predictions from such popular computational methods as homology modeling and automated ligand docking. However, to employ footprinting effectively in this regard, a quantitative understanding of the relationship between solvent accessibility and extent of oxidation must be developed. We are approaching this problem by quantifying the experimental data and by employing a robust method to estimate side-chain $<$ SASA $>$.

\section{Experimental}

\section{Sample Preparation}

Galectin-1, with the sequence characterized by Cho and Cummings [39], was expressed in Chinese hamster ovary $(\mathrm{CHO})$ cells, purified as described previously [39], and stored under reducing conditions in presence of dithiothreitol (DTT) [51], Bio-Rad Laboratories (Hercules, CA). Before laser exposure, DTT was removed by dialysis using Spectra/Por RC Float-A-Lyzer, MW 3500, Spectrum Laboratories Inc. (Rancho Dominguez, CA). Galectin-1 concentration was adjusted to $0.25 \mathrm{mM}$ by adding a 10 times diluted phosphate buffer saline $(0.1 \times$ PBS), Mediatech, Inc. (Herndon, VA). Immediately before laser exposure, the protein solution was mixed with hydrogen peroxide $(10 \%$, by dilution of $30 \%$ solution $w t / w t$ ), Sigma-Aldrich (St. Louis, MO) to a final concentration of $1 \%$, to a final volume of $8 \mu \mathrm{L}$ (final protein concentration $\sim 0.22 \mathrm{mM}$ ).

Synthetic peptides, in greater than $98 \%$ purity were purchased from Biomatic Corporation (Wilmington, DE) and stored as a lyophilized powder. Before laser exposure, each peptide was resuspended in $25 \mathrm{mM}$ ammonium bicarbonate buffer to a concentration of 0.75 $\mathrm{mM}$. An aliquot $(4.2 \mu \mathrm{L})$ of the peptide solution was added to a solution of hydrogen peroxide (10\%) and 25 $\mathrm{mM}$ ammonium bicarbonate (both Sigma-Aldrich) and adjusted to a final concentration of $1 \% \mathrm{H}_{2} \mathrm{O}_{2}$, and the total volume of $8 \mu \mathrm{L}$ (final peptide concentration $\sim 30$ $\mathrm{mM})$. Purified water (18.2 $\mathrm{M} \Omega$ ) for all resuspensions and buffer preparations was obtained from an in-house
NANOpure (Barnstead International, Dubuque, IA) Diamond system.

\section{Laser Photolysis}

Hydroxyl radicals were generated by exposure to radiation from a Compex $110 \mathrm{KrF}$ excimer laser operating at 248 nm, Lambda Physik, Coherent Inc. (Santa Clara, CA). A microcentrifuge tube $(1.5 \mathrm{~mL})$ containing $8 \mu \mathrm{L}$ of the protein or peptide hydrogen peroxide solution was aligned along the beam axis to ensure the maximal contact of the laser beam with the protein solution, at a distance of $12 \mathrm{~cm}$ from the laser source. Each sample was exposed to a single $30 \mathrm{~ns}$ laser pulse with the adjusted laser power of $110 \mathrm{~mJ} /$ pulse. In the case of multiple pulses, a pulse rate of $5 \mathrm{~Hz}$ was employed. Immediately after irradiation, the sample was flashfrozen in liquid nitrogen and lyophilized for $1.5 \mathrm{~h}$ to remove any remaining $\mathrm{H}_{2} \mathrm{O}_{2}$ and water.

\section{Gel Electrophoresis}

Before gel electrophoresis, the lyophilized samples were resuspended in $0.1 \times$ PBS buffer. A premixed running electrophoresis Laemmli sample buffer (62.5 $\mathrm{mM}$ Tris- $\mathrm{HCl}, \mathrm{pH} 6.8,2 \%$ sodium dodecyl sulfate (SDS), $25 \%$ glycerol, $0.01 \%$ bromophenol blue) with addition of $5 \%$ reducing agent $\beta$-mercaptoethanol (both Bio-Rad Laboratories, Hercules, CA) was added to the PBSsample solution in a 2:1 vol/vol ratio. A $4 \%$ to $10 \%$ Tris-tricine SDS gel (Bio-Rad Laboratories) was run under two buffer systems, anode $(0.2 \mathrm{M}$ Tris- $\mathrm{HCl}, \mathrm{pH}$ 8.9 ) and cathode $(0.1 \mathrm{M}$ Tris, $1 \mathrm{M}$ tricine, $1 \%$ SDS, $\mathrm{pH}$ 8.25) [52] to identify any possible protein fragments. Electrophoresis voltage and current conditions were $150 \mathrm{~V}$ and $100 \mathrm{~A}$, respectively, and the length of the run was $1 \mathrm{~h}$ $15 \mathrm{~min}$. After completion of the run, the gel was washed in nanopure water and stained via a silver staining procedure, using SilverSNAP Stain Kit II; Pierce (Rockford, IL) following the manufacturer's protocol.

\section{Proteolytic Digestion}

To prepare the sample for mass spectrometric analysis, the lyophilized protein (or peptide) was resuspended in $15 \mu \mathrm{L}(50 \mathrm{mM})$ ammonium bicarbonate (Sigma-Aldrich) digest buffer. For samples of the protein, dithiothreitol (Bio-Rad Laboratories) was added to a final DTT concentration of $10 \mathrm{mM}$, and the solution heated in a water bath for $1 \mathrm{~h}$ at $60^{\circ} \mathrm{C}$. Iodoacetamide (IAA; SigmaAldrich) was added to the sample to give a final IAA concentration of $50 \mathrm{mM}$, and the sample incubated for $1 \mathrm{~h}$ at room temperature. Finally, sequencing grade modified trypsin, Promega (Madison, WI) was added in a 1:30 (protease:protein) ratio. The $\mathrm{pH}$ of the mixture was determined by pHydrion Papers; Micro Essential Laboratory (Brooklyn, NY) to be between 6 and 8. The sample was then incubated for $18 \mathrm{~h}$ at $37^{\circ} \mathrm{C}$. Digestion 
was quenched by removing the trypsin and salts from the solution by passing through a C-18 ZipTip, Millipore Corporation (Bedford, MA). The galectin-1 digest was eluted from the ZipTip with $10 \mu \mathrm{L}$ of mixed solvent acetonitrile:water:formic acid (50:49.9:0.1 (vol/vol)), dried on a speedvac, and resuspended in $10 \mu \mathrm{L}(0.1 \%$, $\mathrm{vol} / \mathrm{vol}$ ) aqueous solution of formic acid (Sigma-Aldrich) and stored at $6{ }^{\circ} \mathrm{C}$ before analyzed.

\section{ESI-FT and MALDI-TOF}

Single mass spectra were obtained by high-resolution MALDI-TOF, using a 4700 Proteomics Analyzer, Applied Biosystems (Lincoln, CA). In a typical experiment, $0.5 \mu \mathrm{L}$ of each sample was mixed with $0.6 \mu \mathrm{L}$ of 10 $\mathrm{mg} / \mathrm{mL} \quad \alpha$-cyano-4-hydroxycinnamic acid ( $\sigma$-Aldrich) dissolved in ethanol, spotted on a MALDI plate, Applied Biosystems (Foster City, CA) and analyzed in a reflector positive mode with 4200-fixed laser intensity.

Tandem mass spectrometry was performed on a Finnigan LTQ-FT hybrid linear ion trap/Fourier transform ion cyclotron resonance (FTICR) mass spectrometer (7-tesla) with an electrospray ionization source (ESI), Thermo Electron (San Jose, CA), connected to an Agilent 1100 capillary liquid chromatograph (Palo Alto, CA) through a C18 column, $15 \mathrm{~cm} \times 150 \mu \mathrm{m}$, MicroTech Scientific (Vista, CA). To elute peptides from the column, mobile phases $\mathrm{A}, 99.9 \% \mathrm{H}_{2} \mathrm{O} / 0.1 \%$ formic acid (vol/vol), and B, 99.9\% acetonitrile/ $0.1 \%$ formic acid (vol/vol) were used. In a $130 \mathrm{~min}$ run, a gradient from $5 \%$ to $80 \%(\mathrm{vol} / \mathrm{vol}) \mathrm{B}$ was employed at a flow rate of 1 $\mu \mathrm{L} / \mathrm{min}$. MS/MS spectra were acquired on the nine most abundant ion precursors from each MS scan. Raw datasets were converted into mzXML format, followed by conversion to $\mathrm{pkl}$ format, using ReAdW and mzXML2Other [53].

\section{Peak Assignment and Quantitation of Oxidation}

Established software for identification of MS/MS peaks from proteolytic digests, such as Mascot [35] and SEQUEST [34] are not currently well suited for the analysis of datasets that include a large number of post-translational mass modifications, as arise from hydroxyl radical oxidation. Emerging programs, such as MyriMatch [54] and ByOnic [36], have more flexibility in this regard. For peak assignment we employed ByOnic to search against a database containing only the CHO galectin-1 sequence [39], augmented by common mass modifications, as associated with carbamidomethylation of cysteine and oxidation of methionine, as well as 14 potential mass shifts arising from side-chain oxidation. This number of mass modifications leads to over 45 potential oxidation products (Table 1). Most of the expected oxidation products have been previously characterized by the Chance laboratory [11, 55, 56], and some of the less common modifications have been described by Berlett and Stadtman [57] and Kubota et
Table 1. Observed ${ }^{\mathrm{a}}$ mass changes from side chain oxidation

\begin{tabular}{|c|c|c|}
\hline Residue & $\begin{array}{l}\text { Potential mass } \\
\text { changes }\end{array}$ & $\begin{array}{l}\text { Associated modifications } \\
\qquad[55,57]\end{array}$ \\
\hline $\mathrm{C}$ & $-16 ;+32,+48$ & Hydroxy, sulfonic acid \\
\hline $\mathrm{M}$ & $+16 ;-32 ;+32$ & $\begin{array}{l}\text { Sulfoxide, aldehyde, } \\
\text { sulfone }\end{array}$ \\
\hline W & $+16,+32,+48 ;+20$ & $\begin{array}{l}\text { Hydroxy, ring opening, } \\
\text { hydroxykynurenine }\end{array}$ \\
\hline Y & $+16,+32,+48$ & Hydroxy \\
\hline $\mathrm{F}$ & $+16,+32,+48$ & Hydroxy \\
\hline $\mathrm{H}$ & $+16 ;+5,-10,-23,-22$ & Oxo, ring opening \\
\hline $\mathrm{L}$ & $+16 ;+14$ & Hydroxy, carbonyl \\
\hline $\mathrm{I}^{\mathrm{b}}$ & $+16 ;+14$ & Hydroxy, carbonyl \\
\hline V & $+16 ;+14$ & Hydroxy, carbonyl \\
\hline$P$ & $+16 ;+14 ;-30$ & $\begin{array}{l}\text { Hydroxy, carbonyl, } \\
\text { pyrrolidone }\end{array}$ \\
\hline $\mathrm{R}$ & $-43 ;+16 ;+14$ & $\begin{array}{l}\text { Deguanidination, hydroxy, } \\
\text { carbonyl }\end{array}$ \\
\hline $\mathrm{K}^{\mathrm{b}}$ & $+16 ;+14$ & Hydroxy, carbonyl \\
\hline$E$ & $-30 ;+16 ;+14$ & $\begin{array}{l}\text { Decarboxylation, hydroxy, } \\
\text { carbonyl }\end{array}$ \\
\hline Q & $+16 ;+14$ & Hydroxy, carbonyl \\
\hline D & $-30 ;+16$ & Decarboxylation, hydroxy \\
\hline $\mathrm{N}^{\mathrm{b}}$ & +16 & Hydroxy \\
\hline S & $+16 ;-2$ & Hydroxy; $-\mathrm{H}_{2} \mathrm{O}$ \\
\hline $\mathrm{T}^{\mathrm{b}}$ & -2 & $-\mathrm{H}_{2} \mathrm{O}$ \\
\hline$A^{b}$ & +16 & Hydroxy \\
\hline
\end{tabular}

a Observed mass changes shown in boldface.

bow level of oxidation observed $(<2 \%)$.

al. [58]. ByOnic includes three features not found in most database-search programs that make it especially suitable for identifying multiply modified peptides. First, it recalibrates $\mathrm{m} / \mathrm{z}$ measurements based on wellidentified peaks from an initial pass through the data. We defined a well-identified peak to be a singly charged $b$ - or $y$-ion from a peptide identification with $P$-value smaller than 0.001. Unlike SEQUEST or Mascot, ByOnic's scoring algorithm counts a match with $0.1 \mathrm{Da}$ error more heavily than one with $0.2 \mathrm{Da}$ error; hence recalibration offers improved sensitivity and specificity. Second, to improve efficiency, each type of modification has a user-defined limit on the number of occurrences per peptide. For example, up to five modifications per peptide were allowed, with at most four oxidations on reactive residues (cysteine, methionine, histidine, tryptophan, leucine, isoleucine, valine, arginine, phenylalanine, and tyrosine), and at most one on less reactive residues. This is in contrast to other methods that allow a peptide to carry any number of each type of enabled modification. Third, results are double-checked with a "wild-card" modification; this type of search allows any integer change, within user-settable mass limits, to any one residue in each peptide. A wild card can be enabled along with any other set of modifications, and often finds unanticipated chemical artifacts such as sodiation, over-alkylation [59], and carbamidomethylated $N$-termini. Therefore, ByOnic was chosen as the main database search tool for this study. In general, searches were performed with the following search parameters: spec- 
ificity for tryptic fragments, fragment ion tolerance of $0.35 \mathrm{Da}$ (after recalibration), peptide tolerance varied with parent charges (1.5 Da per charge), and including all of the mass modifications listed in Table 1. All oxidation positions were confirmed by tandem MS.

Quantitation of the level of oxidation at each amino acid position was performed using an in-house program that first matched the peptide masses from the LC-MS spectra to the sequences previously identified by ByOnic. The level of oxidation for any given amino acid was then computed by summing the spectral intensities for all peptides containing that amino acid, using the LC-MS spectral intensities for the peptides. The percentage of oxidation on a per-residue basis was then readily computed from eq 1: a representative example of this procedure is presented in Figure S1, which can be found in the electronic version of this article. For reasons of sensitivity, levels of oxidation were computed from LC-MS data rather than from MALDI-TOF data. Although this required a more complex data analysis, it generated a more complete list of oxidation states and therefore led to a more complete understanding of the relationship between solvent accessibility and level of oxidation.

\section{Molecular Modeling}

Since there are no crystal structures of CHO galectin-1, a homology model was generated that was subsequently employed in MD simulations. A template structure (pdb id: 1W6P [60] for the homology model that has $90 \%$ sequence identity with $\mathrm{CHO}$ galectin-1 was identified by searching the National Center for Biotechnology Information (NCBI) BLAST database (www. ncbi.nlm.nih.gov) and retrieved from the Research Collaboratory for Structural Biology (RCSB) database [61]. The model was built using the Molecular Operating Environment (MOE), Chemical Computing Group Inc. (www.chemcomp.com) program. To calculate the $<$ SASA $>$ of each side chain in galectin-1, a 10-ns MD simulation of the complete protein (homodimer), as well as of one subunit of the protein (monomer) was performed using the all-atom AMBER 9 [62] force field with the PARM99 protein parameters [63]. All histidine residues were considered as neutral and were protonated at the $\mathrm{N} \varepsilon$ position. Before the MD simulations, the protein was solvated by 10,600 TIP3P [64] water molecules for the homodimer and 5637 waters for monomer. Counter ions were added to neutralize charge (four $\mathrm{Na}+$ per monomer) using the tLEAP module of AMBER. Each system was subjected to energy minimization (1000 steps of steepest descent and 1000 of conjugate gradient) and heated from $0 \mathrm{~K}$ to the simulation temperature of $300 \mathrm{~K}$ over $50 \mathrm{ps}$. The simulation was performed using the NPT ensemble, at 1 atm using a 2 -fs integration time step. The atomic coordinates were stored every 10 ps for analysis, for a total of 1000 snapshots. SASA values were calculated for individual snapshots employing the NACCESS program [65], with
$<$ SASA $>$ and standard deviations computed over the 10 ns simulation.

\section{Results and Discussion}

\section{Effect of Number of Laser Exposures and Hydrogen Peroxide Concentration on Protein Integrity}

To ensure a high-resolution footprint, it is necessary to minimize the duration of exposure to hydroxyl radical relative to ligand binding kinetics; yet, to observe oxidation an adequate level of hydroxyl radicals is essential. Laser-induced radical formation has the potential to satisfy these requirements [18]. Additionally, the extent of side-chain oxidation may be enhanced by increasing the number of laser exposures, or by increasing the concentration of peroxide [18]; however, extreme oxidation conditions can lead to protein disintegration via back bone cleavage [33]. To examine the effect of these variables on protein integrity, initial experiments were performed with 1, 5, 15, and 25 laser exposures, under a range of hydrogen peroxide concentrations, and the resultant products analyzed by SDSPAGE.

In the case of galectin-1, backbone cleavages were observed (Figure S2) after multiple laser pulses, especially in cases of 15 and 25 shots, which on the sodium dodecyl sulfate polyacrylamide gel electrophoresis (SDS-PAGE) gel can be seen as smaller fragments that migrated between 14 and $5 \mathrm{kDa}$. In addition, there was an obvious decrease in the intensity of galectin- 1 at 14.5 $\mathrm{kDa}$ after 25 laser pulses, which could be attributed to extensive protein degradation. In contrast, the SDSPAGE analysis indicated that increasing the concentration of hydrogen peroxide did not affect protein backbone integrity with a single laser pulse. However, to avoid the potential for protein denaturation [18], we elected to employ a single laser exposure with a $1 \%$ peroxide concentration.

\section{Oxidation Experiments Applied to a Synthetic Peptide}

To confirm that our experimental conditions were able to generate the expected oxidation states without leading to any backbone fragmentation (as suggested by the SDS-PAGE data) a synthetic fragment of galectin-1 (LHFNPR, peptide-1) was subjected to hydroxyl radical oxidation. Peptide-1 corresponds to positions 44-49 in galectin-1 and with $\mathrm{m} / \mathrm{z} 783.4$ (molecular weight of $782.91 \mathrm{Da})$. An examination of the MALDI-TOF data for the oxidized peptide confirmed that there was no backbone cleavage. As expected, the most abundant product was the peptide with a single oxidation (mass change of $+16 \mathrm{Da}, m / z 799.4)$, while the second most abundant product contained two oxidations (+32 Da, $m / z$ 815.4) (Figure 1). Subsequent MS/MS analysis con- 


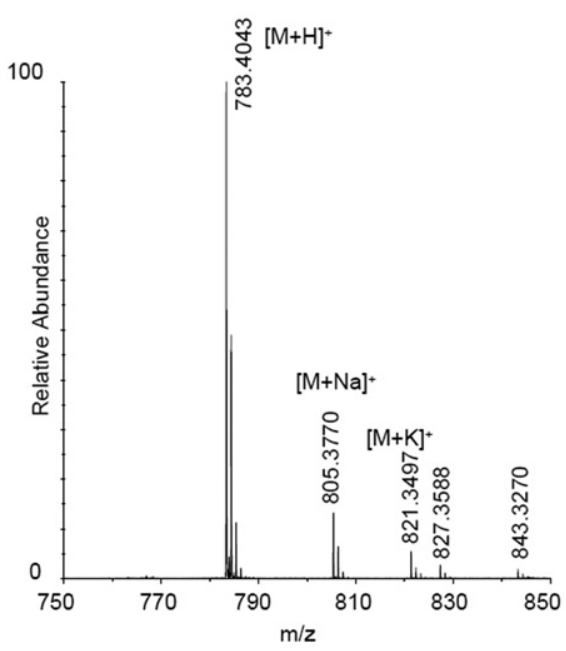

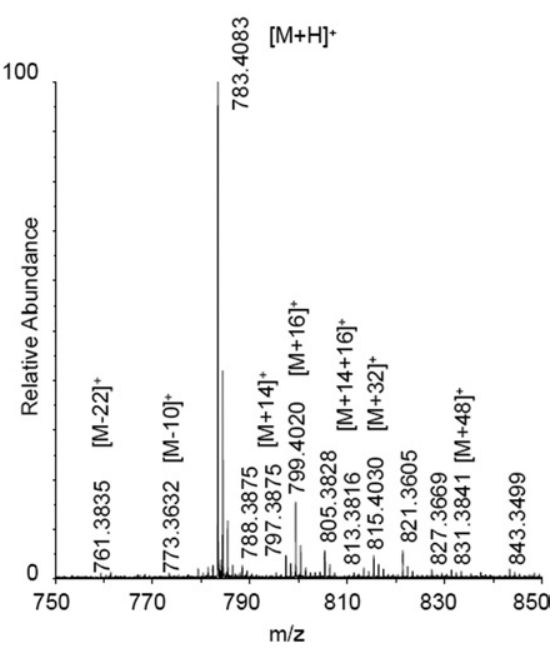

Figure 1. Peptide-1 before (a) and after oxidation (b), indicating oxidation of phenylalanine $(\mathrm{m} / \mathrm{z} 799)$ and histidine $(\mathrm{m} / \mathrm{z} 761$ and 773$)$.

firmed that most of the expected oxidation states were present in the sample. The difference between the MALDI-TOF and LC-MS experiments was in the ability of the FT instrument to detect products of oxidation that were present in very low amounts. By tandem mass spectrometry, histidine oxidation states with mass changes of $+16,-10$, and -22 Da were identified, as well as leucine oxidation products with +16 and +14 mass changes, and proline with addition of 14 Da. Phenylalanine was found in three oxidation states with addition of 16, 32, and 48 Da. Some of these higher oxidation products were also identified in the MALDITOF spectrum, but in such low quantities that in other circumstances these would be most likely considered as noise.

Not all of the possible oxidation states were identified for the residues in peptide-1, for example neither arginine nor asparagine were oxidized. Nonetheless, the extent of oxidation was deemed sufficient to warrant application of this method to intact galectin- 1 . Before that, however, we continued with the examination of synthetic peptides to determine the extent to which the level of oxidation could be quantified from spectral intensities.

\section{Quantitation of Level of Oxidation}

To confirm that spectral intensities may be employed to quantify the extent of oxidation, as defined in eq 1, samples of two additional synthetic peptides, which represent oxidized fragments of galectin-1, were prepared in known concentrations. In peptide-2 (LHYNPR), the phenylalanine has been replaced by a tyrosine in position three. This substitution results in a net change of $16 \mathrm{Da}$ and is equivalent to an oxidation product of the phenylalanine. Similarly, peptide-3 (LDFNPR), is also an oxidized form of peptide-1. In peptide-3, the histidine was replaced by an aspartic acid, which is a net mass change of $-22 \mathrm{Da}$. At an advanced stage of histidine oxidation, the ring of the histidine side chain opens, and two amino groups and a carbonyl group are replaced by a carboxyl group, which results in a loss of $22 \mathrm{Da}[11,15]$. A summary of the peptide molecular weights, amino acid replacements, and the net molecular weight changes is presented in Table 2.

Mixtures of each of the peptides containing representative oxidations (peptide-2 and peptide-3) with the nonoxidized material (peptide-1) were prepared in the following ratios peptide-1:peptide-2 (60:40) and peptide-1:peptide3 (33:66). Additionally, a sample containing all three peptides was prepared in a ratio of peptide-1:peptide-2:peptide3 (50:25:25). From the peak intensities of the peptides in each sample, the levels of oxidation for phenylalanine and histidine were determined (eq 1, Table 3). The intensities for all peptides in each sample were determined using both MALDI-TOF and LC-MS experiments. To be consistent with the proposed analysis of galectin-1, all mass spectrometry data for the synthetic samples were processed using the ByOnic software, followed by intensity summation on a per-residue basis using an in-house program. In general, both mass spectrometric methods resulted in close agreement with each other and with the known concentrations. Quantitation using the LC-MS data were only

Table 2. Synthetic peptides used in quantification studies

\begin{tabular}{ccccl}
\hline Peptide & Sequence & $\mathrm{m} / \mathrm{z}$ & $\begin{array}{c}\text { Mass } \\
\text { change }\end{array}$ & $\begin{array}{c}\text { Oxidation } \\
\text { equivalent }\end{array}$ \\
\hline \hline 1 & LHFNPR & 782.91 & & Nonoxidized \\
2 & LHYNPR & 798.91 & $+16 \mathrm{Da}$ & F3Y \\
3 & LDFNPR & 760.85 & $-22 \mathrm{Da}$ & H2D \\
\hline
\end{tabular}


Table 3. Oxidation level equivalents for mixtures of synthetic peptides

\begin{tabular}{|c|c|c|c|c|}
\hline \multirow[b]{2}{*}{ Method } & \multirow{2}{*}{$\begin{array}{c}\text { Pep-1 and Pep-2 } \\
\text { F oxid }-40 \% \\
m / z 799 \text { oxidation (\%) }\end{array}$} & \multirow{2}{*}{$\begin{array}{c}\text { Pep-1 and Pep-3 } \\
\text { H oxid }-66 \% \\
m / z 761 \text { oxidation (\%) }\end{array}$} & \multicolumn{2}{|c|}{$\begin{array}{c}\text { Pep- } 1 \text {, pep-2 and pep-3 } \\
F \text { and } H \text { oxid }-25 \% \text { each }\end{array}$} \\
\hline & & & m/z 799 oxidation (\%) & $m / z 761$ oxidation (\%) \\
\hline MALDI-TOF & $41.9(1.2)^{a}$ & $64.1(2.8)$ & $24.5(0.8)$ & $26.5(0.7)$ \\
\hline LC-MS & $42.8(2.1)$ & $66.4(6.6)$ & $23(1.2)$ & $27.4(2.7)$ \\
\hline
\end{tabular}

a Standard deviation in parentheses.

slightly less accurate than the high-resolution MALDI data. In the case of the phenylalanine oxidation (peptide-1:peptide-2) a maximum error of $2 \%$ with respect to the known concentrations was observed, while for the histidine oxidation (peptide-1:peptide-3) a slightly higher error of $6 \%$ was noted. In the third test case, the ratio of all three peptides was determined. Again, there was generally good agreement between the known ratios and the intensity-determined values for each mass spectrometry method. As seen in the simple mixtures, the measured level of phenylalanine oxidation ( $24 \%$ by MALDI-TOF, $26 \%$ by LC-MS) was in slightly better agreement with the known concentration $(25 \%)$ than for the histidine oxidation product $(22 \%$ by MALDI-TOF, $28 \%$ by LC-MS). The fact that the ESI and MALDI data were in good agreement with each other and with the expected values suggests that each of the peptides displayed similar ionization efficiencies, although that the "oxidation" of histidine to aspartate $(-22)$ might be expected to impact the net charge. Generally, the dominant charge state for these peptides under the ionization conditions used was +1 . Previous studies of a peptide containing both a histidine and an arginine side chain indicated that the first protonation occurred on exclusively on the arginine [66]. Eliminating the histidine would leave the arginine as the dominant basic site, and replacing it with an aspartate should not significantly alter the surface activity in the droplet for the ESI experiments $[67,68]$. Therefore, under electrospray ionization conditions where the +1 charge state dominates, it is not surprising to find that the replacement of a histidine with an aspartate does not significantly alter the ionization efficiency of the arginine-containing peptide.

\section{Extent of Oxidation of Galectin-1 from Single Laser Exposure}

An examination of the high-resolution MALDI-TOF spectra of the tryptic digest of oxidized galectin-1 clearly indicated that a single laser pulse in the presence of $1 \%$ hydrogen peroxide induced significant oxidation of the protein (Figure 2). As a result of the oxidation, intensities of nonoxidized peptides decreased, for example in the peptides with $m / z$ 1486, 1142, 1041, and 942, while numerous new peaks resulting from sidechain oxidation appeared. To fully characterize the sites of oxidation, tandem mass spectrometry with further fragmentation of peptides was performed.

Employing ByOnic to search against a database comprised of the sequence of galectin-1, allowing for 14 known mass changes from oxidation, led to the observation of 43 unique side-chain oxidation products

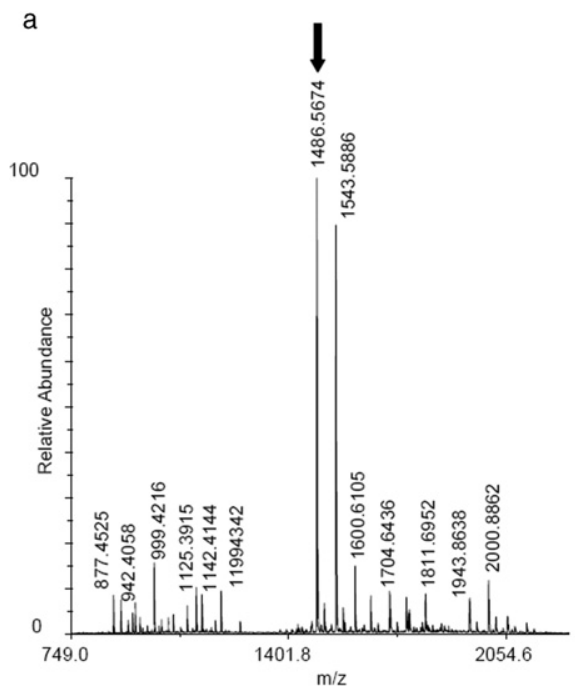

b

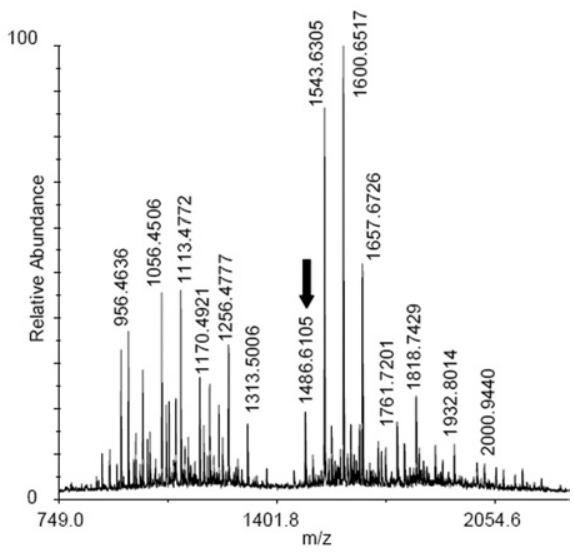

Figure 2. MS spectrum of tryptic digestion of galectin-1 before oxidation (a), and after oxidation (b). Oxidation leads to more facile proteolysis, formation of peaks from oxidation products, and a decrease in the abundance of non-oxidized peptides (see peak indicated by arrows). 

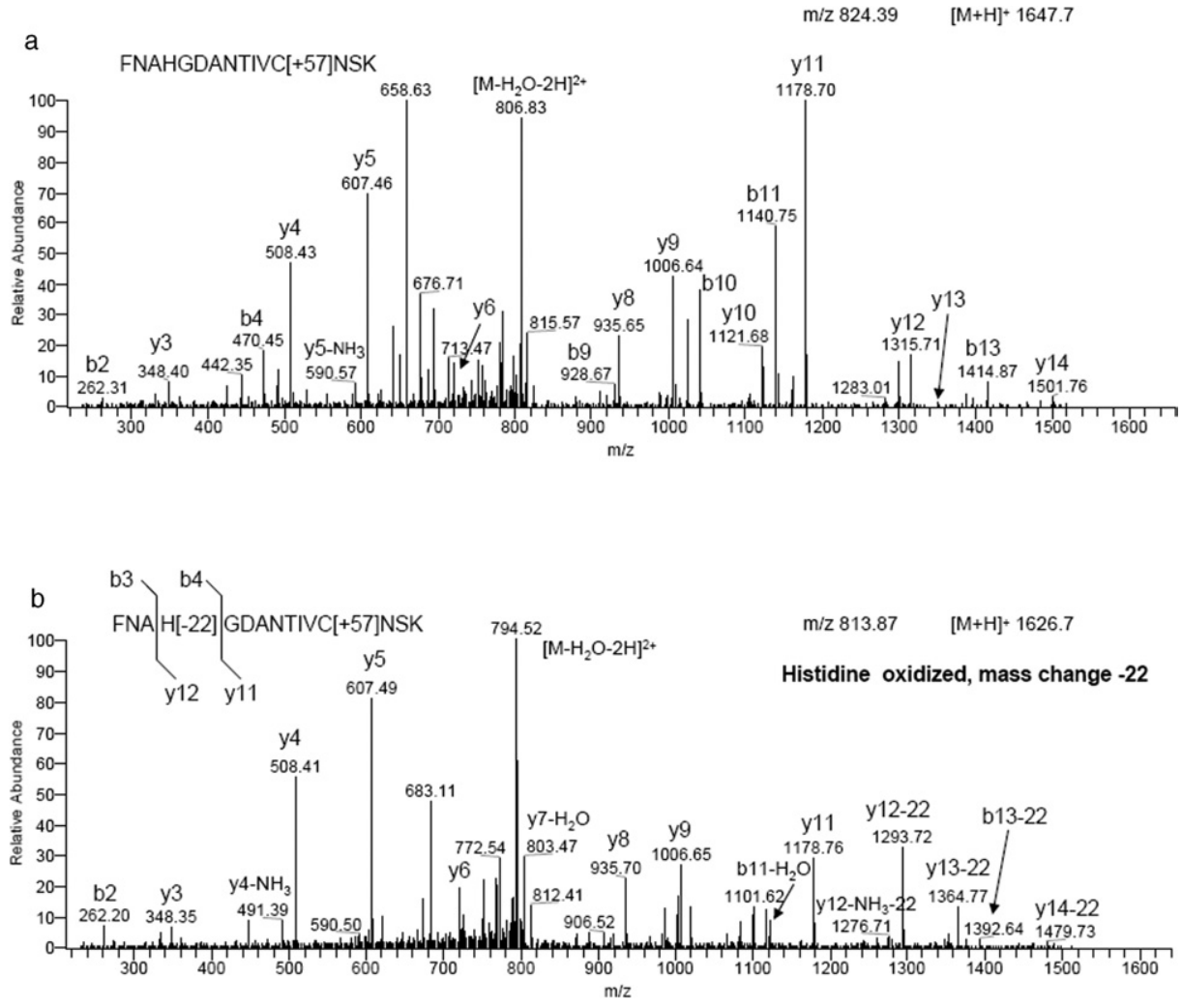

Figure 3. Tandem mass spectra of a tryptic peptide from galectin-1 in nonoxidized (a) and oxidized (b) forms indicating peaks associated with a 22 Da mass loss, typical of histidine oxidation.
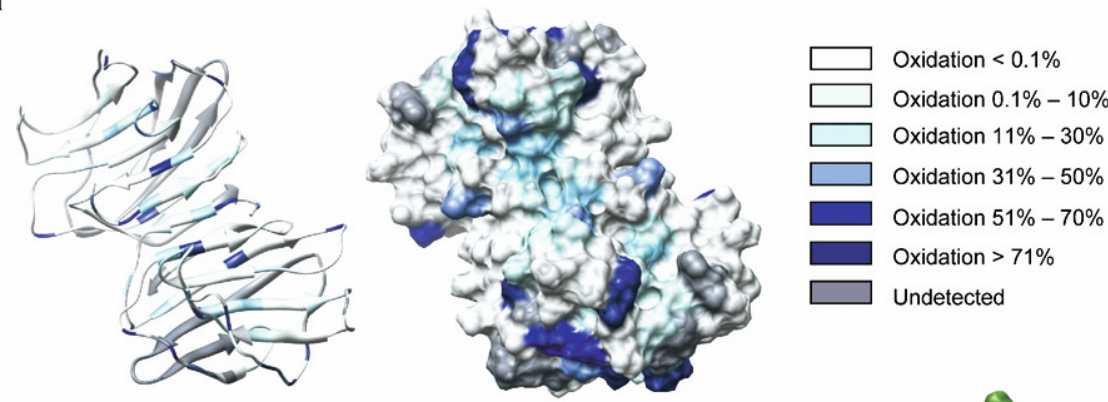

b

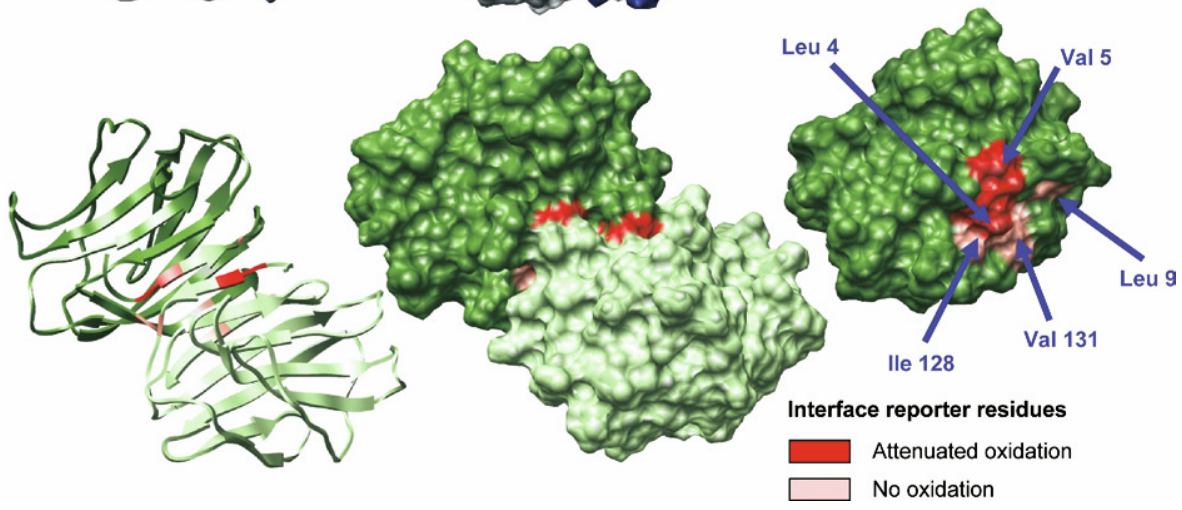

Figure 4. Per-residue oxidation levels plotted on the solvent accessible surface of dimeric galectin-1 (a). Galectin-1 dimer interface in detail. Reporter residues are indicated in shades of red according to the measured level of side-chain oxidation. From left: ribbon structure of the homodimer, solvent accessible surface structure of the homodimer, and monomeric subunit illustrating interfacial residues $(\mathbf{b})$. 
Table 4. Per-residue oxidation levels and side chain $<$ SASA $>$ values for galectin-1

\begin{tabular}{|c|c|c|c|c|c|c|c|}
\hline \multirow[b]{2}{*}{ Residue } & \multirow{2}{*}{$\frac{\text { Oxidation [\%] }}{\text { Dimer }}$} & \multicolumn{2}{|c|}{$<\mathrm{SASA}>\left[\AA^{2}\right]$} & \multirow[b]{2}{*}{ Residue } & \multirow{2}{*}{$\frac{\text { Oxidation [\%] }}{\text { Dimer }}$} & \multicolumn{2}{|c|}{$<\mathrm{SASA}>\left[\AA^{2}\right]$} \\
\hline & & Dimer & Monomer & & & Dimer & Monomer \\
\hline $\mathrm{A} 1$ & $0.0(0.0)^{a}$ & $57(14)$ & $82(2)$ & $\mathrm{K} 28$ & $0.0(0.0)$ & $112(11)$ & $114(8)$ \\
\hline A6 & $0.1(0.1)$ & $8(4)$ & $34(4)$ & K36 & $0.1(0.0)$ & 99 (13) & 115 (8) \\
\hline A24 & $0.0(0.0)$ & $38(8)$ & $17(6)$ & K63 & $0.0(0.0)$ & $33(7)$ & $31(4)$ \\
\hline A27 & $0.0(0.0)$ & $10(4)$ & $0(0)$ & K99 & n.d. & $87(12)$ & $86(7)$ \\
\hline A51 & $0.0(0.0)$ & $18(6)$ & 21 (4) & K107 & $0.0(0.0)$ & $97(8)$ & $101(12)$ \\
\hline A55 & $0.0(0.0)$ & $40(6)$ & $46(4)$ & K127 & $0.0(0.0)$ & $119(15)$ & $134(17)$ \\
\hline A67 & $0.0(0.0)$ & $62(4)$ & $64(2)$ & K129 & $0.0(0.0)$ & 75 (18) & $113(20)$ \\
\hline A76 & $0.0(0.1)$ & $44(12)$ & $41(5)$ & L4 & $56.1(12.4)$ & $16(8)$ & $67(8)$ \\
\hline A94 & $n \cdot d^{b}$ & $57(5)$ & $57(3)$ & L9 & $0.0(0.0)$ & $3(2)$ & $14(4)$ \\
\hline A116 & $0.0(0.0)$ & $35(11)$ & $27(6)$ & L11 & $13.3(8.6)$ & $8(6)$ & $3(2)$ \\
\hline A121 & $1.9(3.1)$ & $11(3)$ & $11(2)$ & L17 & $0.0(0.0)$ & $3(3)$ & $1(1)$ \\
\hline A122 & $0.0(0.0)$ & $6(5)$ & $4(1)$ & L32 & $0.0(0.0)$ & $11(6)$ & $5(2)$ \\
\hline A132 & $1.5(2.6)$ & $15(6)$ & $50(4)$ & L34 & $0.0(0.1)$ & $4(3)$ & $1(1)$ \\
\hline $\mathrm{C} 2$ & $41.9(9.7)$ & $85(9)$ & $71(4)$ & L41 & $12.5(7.2)$ & $5(3)$ & $3(2)$ \\
\hline C16 & $18.7(4.0)$ & $29(10)$ & $34(9)$ & L43 & $20.7(6.6)$ & $3(2)$ & $1(1)$ \\
\hline C42 & 54.9 (7.8) & $1(2)$ & $0(1)$ & L96 & n.d. & $1(2)$ & $0(0)$ \\
\hline $\mathrm{C} 60$ & $5.8(1.4)$ & $2(2)$ & $0(0)$ & L100 & $8.9(7.8)$ & $10(8)$ & $0(0)$ \\
\hline $\mathrm{C} 88$ & n.d. & $23(8)$ & $15(5)$ & L112 & n.d. & $25(10)$ & $12(3)$ \\
\hline $\mathrm{C} 130$ & $0.0(0.0)$ & $25(8)$ & $68(7)$ & M114 & $94.0(2.5)$ & $21(9)$ & $27(7)$ \\
\hline D26 & $0.0(0.0)$ & $100(6)$ & $88(12)$ & M120 & $83.8(10.2)$ & $6(5)$ & $3(2)$ \\
\hline D37 & $2.6(0.5)$ & 55 (8) & $50(5)$ & N8 & $0.0(0.0)$ & 49 (10) & $109(4)$ \\
\hline D54 & $0.0(0.0)$ & $23(4)$ & $16(2)$ & N10 & $0.0(0.0)$ & $86(13)$ & $86(6)$ \\
\hline D64 & $0.0(0.0)$ & $65(9)$ & $76(5)$ & N33 & $0.0(0.1)$ & $20(4)$ & $24(2)$ \\
\hline D92 & n.d. & $67(6)$ & $70(5)$ & N39 & $0.9(1.3)$ & $61(8)$ & $67(4)$ \\
\hline D95 & n.d. & $45(8)$ & $38(5)$ & N40 & $0.0(0.0)$ & $29(8)$ & $33(6)$ \\
\hline D102 & $1.5(1.3)$ & $98(16)$ & $72(4)$ & N46 & $0.6(1.1)$ & $10(4)$ & $8(2)$ \\
\hline D123 & $1.0(0.9)$ & $38(10)$ & $65(5)$ & N50 & $0.0(0.0)$ & $90(6)$ & $96(6)$ \\
\hline D125 & $0.0(0.0)$ & 69 (9) & $29(6)$ & N56 & $0.0(0.0)$ & $87(9)$ & $82(5)$ \\
\hline E15 & $0.0(0.0)$ & $68(30)$ & $37(11)$ & N61 & $0.0(0.1)$ & $11(4)$ & $10(2)$ \\
\hline E22 & $0.0(0.0)$ & $86(13)$ & $67(10)$ & N65 & $0.0(0.0)$ & $99(7)$ & $109(3)$ \\
\hline E71 & $0.1(0.2)$ & $66(8)$ & $49(4)$ & N110 & $0.0(0.0)$ & $1(1)$ & $5(1)$ \\
\hline E74 & $10.4(11.1)$ & $37(10)$ & $30(5)$ & N113 & $0.0(0.1)$ & $89(9)$ & $118(5)$ \\
\hline E86 & n.d. & 50 (14) & $35(8)$ & N118 & $0.0(0.0)$ & $47(8)$ & $58(5)$ \\
\hline E105 & $0.0(0.0)$ & $75(10)$ & 77 (9) & P13 & $0.0(0.0)$ & $36(9)$ & $37(5)$ \\
\hline E115 & $0.0(0.0)$ & 104 (15) & $119(9)$ & P25 & $55.1(9.0)$ & $96(4)$ & $91(5)$ \\
\hline E134 & n.d. & 95 (14) & 77 (18) & P47 & $0.1(0.1)$ & $1(1)$ & $0(0)$ \\
\hline F30 & $0.1(0.1)$ & $7(3)$ & $2(2)$ & P75 & $91.6(7.5)$ & $103(4)$ & $60(4)$ \\
\hline F45 & $18.5(12)$ & $7(5)$ & $2(2)$ & P78 & n.d. & 36 (12) & $26(3)$ \\
\hline $\mathrm{F} 49$ & $3.5(2.8)$ & $8(3)$ & $10(2)$ & P81 & n.d. & $38(7)$ & $54(6)$ \\
\hline F77 & $94.8(7.6)$ & $14(7)$ & $15(3)$ & P101 & $7.4(4.1)$ & 56 (17) & $33(2)$ \\
\hline F79 & n.d. & $10(6)$ & $3(1)$ & P109 & $35.9(7.4)$ & $68(7)$ & $57(3)$ \\
\hline F91 & n.d. & $4(2)$ & $1(1)$ & Q80 & n.d. & $114(12)$ & $122(6)$ \\
\hline F106 & n.d. & $18(6)$ & $14(2)$ & Q93 & n.d. & $87(20)$ & 94 (19) \\
\hline F108 & n.d. & $5(3)$ & $0(0)$ & $\mathrm{R} 20$ & $98.9(0.4)$ & 118 (14) & 109 (10) \\
\hline F126 & $0.0(0.0)$ & $6(5)$ & $6(3)$ & $\mathrm{R} 48$ & $6.1(1.7)$ & $31(8)$ & $7(3)$ \\
\hline F133 & n.d. & $21(9)$ & 70 (13) & $\mathrm{R} 73$ & n.d. & $78(6)$ & $83(8)$ \\
\hline G3 & $0.0(0.0)$ & $8(3)$ & $23(2)$ & $\mathrm{R} 111$ & $54.4(9.1)$ & $65(8)$ & $66(4)$ \\
\hline G14 & $0.0(0.0)$ & $36(4)$ & $31(2)$ & $\mathrm{S7}$ & $5.1(1.4)$ & $37(6)$ & 54 (5) \\
\hline $\mathrm{G} 21$ & $0.0(0.0)$ & $1(1)$ & $0(0)$ & $\mathrm{S} 29$ & $0.0(0.0)$ & $14(6)$ & $21(3)$ \\
\hline G35 & $0.0(0.0)$ & $0(0)$ & $0(0)$ & S38 & $35.9(2.0)$ & $55(6)$ & $53(3)$ \\
\hline G53 & $0.0(0.0)$ & $38(4)$ & $41(1)$ & $\mathrm{S} 62$ & $4.2(0.4)$ & $4(2)$ & $5(1)$ \\
\hline G66 & $0.0(0.0)$ & $19(5)$ & $10(2)$ & S83 & n.d. & $28(7)$ & $35(4)$ \\
\hline G69 & $0.0(0.0)$ & $20(3)$ & $18(1)$ & T57 & $0.0(0.0)$ & $24(5)$ & $29(3)$ \\
\hline G82 & n.d. & $14(4)$ & $18(3)$ & T70 & $0.0(0.0)$ & $102(6)$ & $104(3)$ \\
\hline G103 & $0.0(0.0)$ & $31(4)$ & $23(4)$ & T84 & n.d. & $60(10)$ & 76 (13) \\
\hline G124 & $0.0(0.0)$ & $11(6)$ & $24(2)$ & T90 & n.d. & $41(11)$ & $47(5)$ \\
\hline $\mathrm{H} 44$ & $4.5(1.1)$ & $33(8)$ & $27(4)$ & T97 & n.d. & $19(6)$ & $23(7)$ \\
\hline H52 & n.d. & 116 (17) & $113(8)$ & V5 & $18.6(8.6)$ & $38(10)$ & $78(8)$ \\
\hline $\mathrm{H} 72$ & $92.1(14.8)$ & 74 (11) & $50(5)$ & V19 & $0.0(0.0)$ & $4(3)$ & $1(1)$ \\
\hline $\mathrm{H} 104$ & $5.0(5.7)$ & 62 (19) & $87(11)$ & V23 & $0.0(0.0)$ & $2(2)$ & $0(0)$ \\
\hline 158 & $0.0(0.0)$ & $2(2)$ & $0(0)$ & V31 & $15.8(1.3)$ & $32(7)$ & $28(2)$ \\
\hline 189 & n.d. & $8(5)$ & $3(2)$ & V59 & $0.0(0.0)$ & $4(2)$ & $2(1)$ \\
\hline
\end{tabular}


Table 4. Continued

\begin{tabular}{|c|c|c|c|c|c|c|c|}
\hline \multirow[b]{2}{*}{ Residue } & \multirow{2}{*}{$\frac{\text { Oxidation [\%] }}{\text { Dimer }}$} & \multicolumn{2}{|c|}{$<\mathrm{SASA}>\left[\AA^{2}\right]$} & \multirow[b]{2}{*}{ Residue } & \multirow{2}{*}{$\frac{\text { Oxidation [\%] }}{\text { Dimer }}$} & \multicolumn{2}{|c|}{$<\mathrm{SASA}>\left[\AA^{2}\right]$} \\
\hline & & Dimer & Monomer & & & Dimer & Monomer \\
\hline 198 & n.d. & $3(3)$ & $0(1)$ & V85 & n.d. & $10(6)$ & $6(1)$ \\
\hline I117 & $0.0(0.0)$ & $1(1)$ & $1(1)$ & V87 & n.d. & $7(4)$ & $2(1)$ \\
\hline $\mid 128$ & $0.0(0.0)$ & $14(10)$ & $13(3)$ & V131 & $0.0(0.0)$ & $12(6)$ & $28(8)$ \\
\hline K12 & $0.0(0.0)$ & 107 (15) & $97(10)$ & W68 & $96.9(3.3)$ & $105(9)$ & $108(8)$ \\
\hline K18 & $0.0(0.0)$ & 64 (10) & $109(9)$ & Y119 & $17.3(22.1)$ & $32(6)$ & $31(4)$ \\
\hline
\end{tabular}

aStandard deviation in parentheses.

${ }^{b}$ Oxidation level not determined due to excessive uncertainty in measurement or peak assignment.

(Table 1). Oxidation of the intact protein led to the identification of additional oxidation products, relative to the data obtained for synthetic peptide-1, for example, for arginine and asparagine. An example of the appearance of an oxidized peptide in the tandem MS spectrum of a tryptic peptide from galectin-1 (FNAHGDANTIVCNSK) before and after laser exposure is presented in Figure 3. The MS/MS data clearly identified the oxidation of the histidine residue $(-22 \mathrm{Da})$. Sequence coverage of galectin1 as determined by MS/MS sequencing of tryptic fragments was satisfactory over triplicates of the experiments ( $\sim 85 \%$ on average). Of these identified residues, $\sim 42 \%$ displayed oxidation after a single laser exposure (Figure 4a). A quantified list of the total oxidation level observed for each residue is presented in Table 4.

Because some residues will be on the protein surface, and therefore exposed to hydroxyl radicals, while others will be occluded in the core of the protein, it is important to determine the percentage of residues that might be expected to react, based on their exposure on the surface of the protein and on their chemical susceptibility to oxidation. To relate the oxidation data to the 3D structure of the protein, it is necessary to determine the accessibility of each amino acid side chain to hydroxyl radical. Since hydroxyl radical is essentially the same size as water, it is reasonable to assume that, for a given side chain, the extent of oxidation will be related to SASA of the side chain. This assumption has been qualitatively demonstrated by previous hydroxyl radical oxidation studies $[19,21]$. While SASA values may be determined directly from any 3D structure, to account for side-chain motion in solution at room temperature, we believe a more robust approach is to determine average $<$ SASA $>$ values by MD simulation of the protein, rather than from a single static structure, such as a homology model or X-ray structure. As indicated from the standard deviations in the $<$ SASA $>$ values computed from the MD data (Table 4), side-chain motion can lead to significant variations, which are not taken into account when only a single structure is employed in the analysis.

\section{Relationship Between Side-Chain Oxidation Levels and Solvent Accessibility}

From 1000 snapshots extracted from a 10 ns MD simulation of the galectin-1 homodimer, the average $<$ SASA $>$ of each amino acid side chain for all 134 residues was calculated (Figure 5 and Table 4). To quantify the correlation between the observed oxidation levels and the calculated $<$ SASA $>$ values, the experimental and theoretical data were compiled for each amino acid side chain. By plotting oxidation level versus $<$ SASA $>$ value, for each side chain of the same

Galectin-1 SASA values for monomer (pink) and dimer (black)

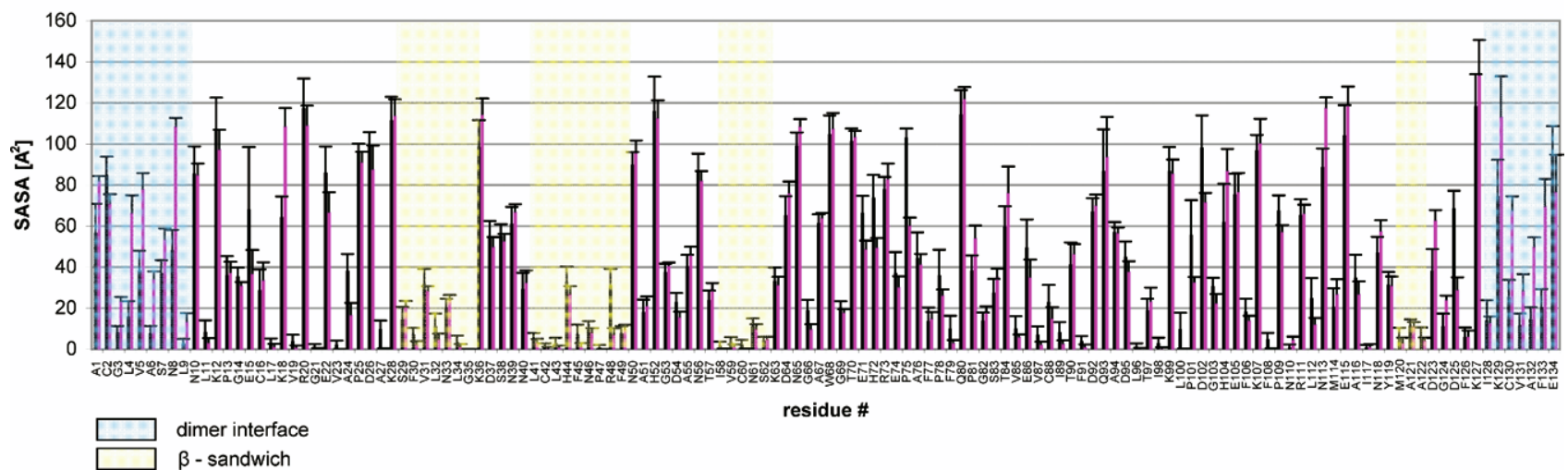

Figure 5. Solvent accessible surface area $(<\mathrm{SASA}>$ ) for each of the 134 side chains in galectin-1. Values for monomer (pink) and dimer (black) domains are reported. Shaded regions indicate the dimer interface (blue). Other regions of low exposure include the sheets associated with the $\beta$-sandwich structure (yellow). 


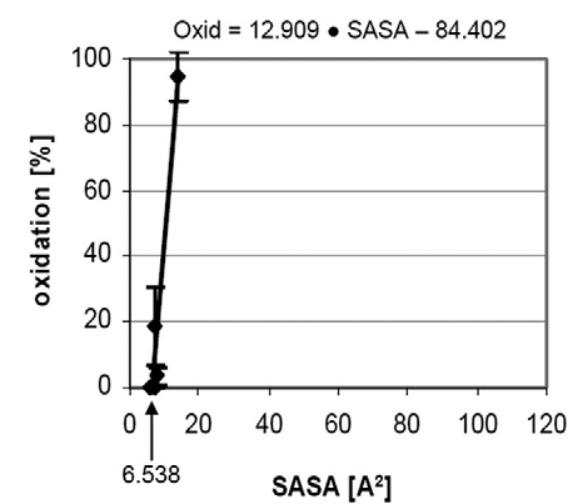

C

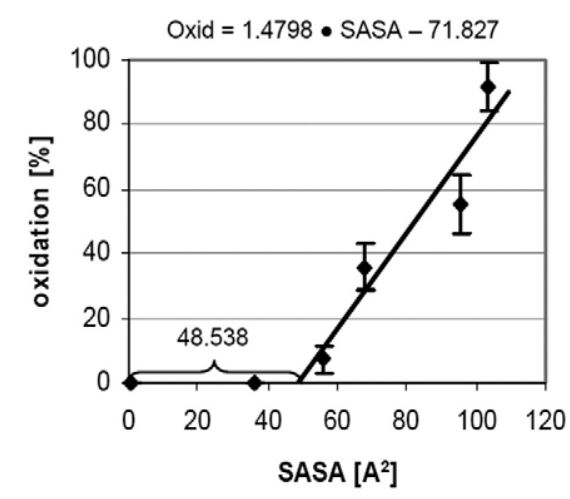

e

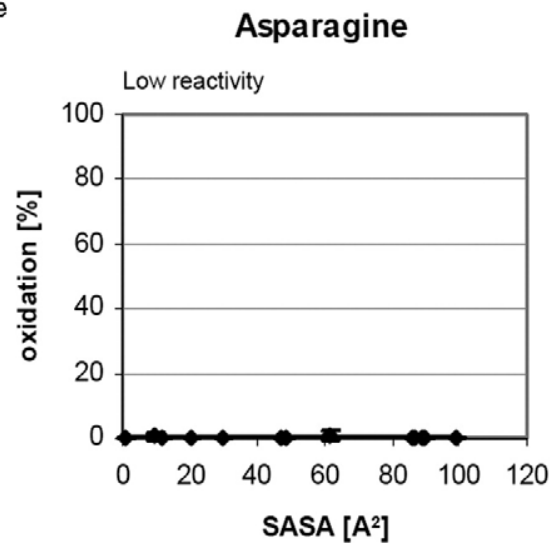

b

Leucine

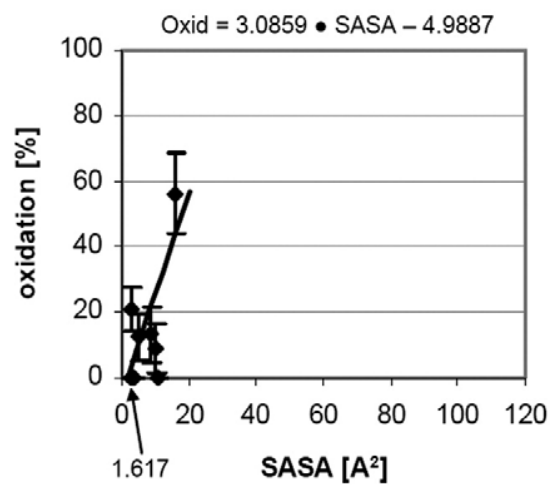

d

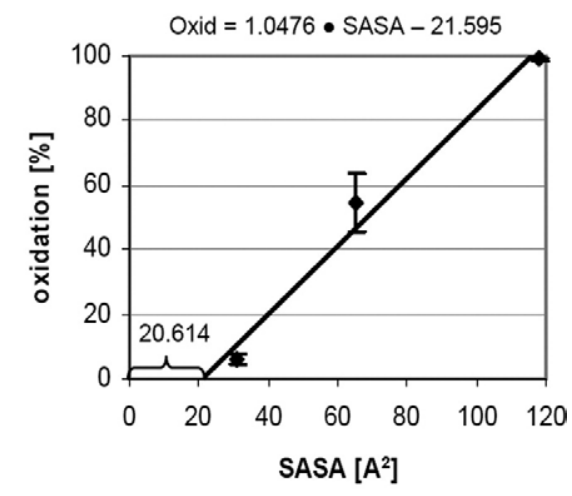

f

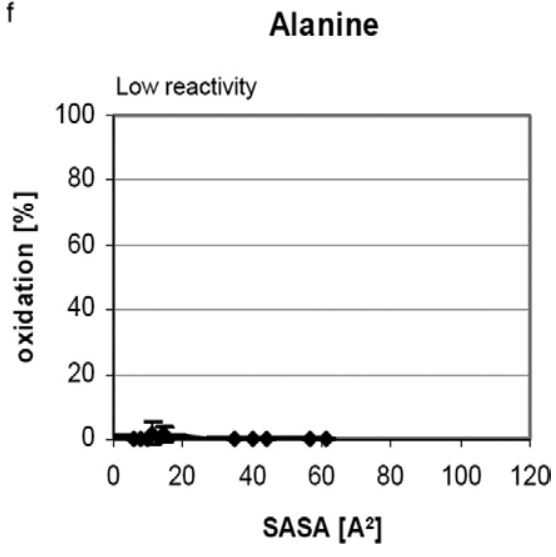

Figure 6. Percentage of oxidation versus side-chain $<$ SASA $>$ for selected amino acids. Highly reactive side chains (a), (b) are characterized by steep slopes $\left(\% \mathrm{Ox} / \AA^{2}\right.$ and low minimal exposure values $\left(\AA^{2}\right.$. Moderately reactive side chains $(\mathbf{c})$, (d) require significant exposure before oxidization may occur. Side chains that are inert under these experimental conditions (e), (f) show no sensitivity to level of exposure.

type, a linear relationship between $<$ SASA $>$ and extent of oxidation was observed (Figure 6). Additionally, for most side chains, a minimum solvent exposure appeared to be required to enable any oxidation to occur. The level of exposure required varied according to the side chain, from a low of $2 \AA^{2}$ for leucine to a high of $\sim 48 \AA^{2}$ for proline. The relationship naturally also depends on the chemical susceptibility of the side chain to oxidation, and to a far lesser extent on the local primary sequence [69]. Additionally, under the conditions employed here, some side chains remained essentially unoxidized regardless of their exposure. From the 
slopes of the plots of $<$ SASA $>$ versus percent oxidation, the side chains could be divided into categories according to their reactivity (high, medium or low). For example, highly reactive residues such as phenylalanine could be characterized by $12.9 \%$ oxidation $/ \AA^{2}$, whereas a medium reactivity residue, such as arginine or proline would result in only $1 \%$ to $2 \%$ oxidation $/ \AA^{2}$. This simple analysis neglects the precise details of the atomic site of reactivity, but nevertheless demonstrated the direct dependence of oxidation level on side-chain exposure. From each reactivity group, two plots of the oxidation level dependence on the $<$ SASA $>$ are shown in Figure 6. The extent to which these relationships are transferable to other proteins is currently under investigation. However, the analysis presented here agrees well with earlier characterization of side-chain reactivity to hydroxyl radical $[55,56]$. Generally, highly reactive amino acids include cysteine, methionine, the aromatics, and leucine. The medium reactivity category includes arginine and proline, while the remaining amino acids such as asparagine, aspartic acid, serine, lysine, glutamine, glutamic acid, threonine, and alanine have low reactivities. Having derived a quantitative relationship between SASA and percent oxidation, it is possible in principle to predict the extent of oxidation that should be observed, given the 3D structure of a protein. To test the accuracy of such predictions as well as the sensitivity of the experimental method to 3D structure, these techniques were applied to the characterization of the interface region between monomeric domains in galectin-1.

\section{Characterization of the Galectin-1 Dimer Interface}

Most amino acid side chains were found to be reactive to some extent under the current experimental conditions (Table 1); however, the following residues were consistently observed to be sensitive to oxidation: cysteine, methionine, tryptophan, tyrosine, phenylalanine, histidine, leucine, valine, proline, arginine. Although an experiment in which differences in oxidation levels between the monomer and dimer were observed would be well suited to characterize the dimer interface, galectin-1 cannot be obtained in monomeric form. In contrast, computationally, both species are amenable to examination. Thus, by examining the difference in the computed <SASA $>$ values from independent $10 \mathrm{~ns}$ MD simulations of the dimer and monomer, the interface region was readily identified (residues 1-9 and 128-143), in agreement with those residues identified in the X-ray structure of the dimer [60]. A subset of reporter residues in the interface (L4, V5, L9, I128, V131, and F133) was identified on the basis that they were predicted to be at least partially shielded from solvent in the interface, and that were likely to be reactive. The observed oxidation levels for these residues are presented in Table 5 and illustrated in Figure $4 \mathrm{~b}$. With the exception of F133, which was not identified in the MS/MS data, the oxidation levels were markedly lower for these interfacial residues than would be expected for
Table 5. Experimentally-measured and $<$ SASA $>$-derived oxidation levels for reporter residues in the galectin-1 dimer interface

\begin{tabular}{lcccccc}
\hline & \multicolumn{2}{c}{ Oxidation [\%] } & & \multicolumn{2}{c}{$\left\langle\right.$ SASA $>\left[\AA^{2}\right]$} \\
\cline { 2 - 3 } \cline { 5 - 6 } Residue & measured & predicted & & dimer & monomer \\
\hline \hline L4 & 56 & 44 & & 16 & 67 \\
L9 & 0 & 4 & & 3 & 14 \\
V5 & 19 & 18 & & 38 & 78 \\
V131 & 0 & 4 & & 12 & 28 \\
I128 & 0 & 0 & & 14 & 13 \\
\hline
\end{tabular}

exposed residues. Notably, the predicted oxidation levels for the dimer, based on the relationships derived above, were in good agreement with the observed values.

The observation that L4 and V5 are significantly oxidized (56\% and 19\%, respectively) despite being associated with the interface [60], suggests that easily oxidized side chains must be highly excluded from solvent to prevent their oxidation under these reaction conditions. Both L4 and V5 have reduced solvent accessibilities relative to their $<\mathrm{SASA}>$ in the galectin-1 monomeric domain ( $\sim 75 \%$ and $50 \%$, respectively); however, this is not sufficient to prevent their partial oxidation. By employing the linear relationship between percentage oxidation and SASA, it is possible to predict the level of oxidation for each of the residues in the interface (Table 5). Notably, the predicted oxidation levels for L4 (44\%) and V5 (18\%) are in good agreement with the observed values. These relationships need to be confirmed by analysis of further proteins; however, they appear to offer a promising approach to relating observed oxidation to 3D structure.

As expected, residues in the interface with very low $<$ SASA $>$ values were not found to be oxidized, for example L9, I128, and V131. Other residues that are associated with the dimer interface, but which have very low reactivity levels, did not get oxidized regardless of their solvent exposure (A1, A6, S7, N8, K129, E134), which illustrates the benefit of identifying a sub-set of reporter residues before attempting to interpret the oxidation data purely in terms of 3D structure effects.

\section{Conclusions}

A combined experimental and theoretical approach directly applicable to protein surface mapping has been presented. A linear relationship between the level of side-chain oxidation and average $<$ SASA $>$ derived from MD simulation data, has been derived. Notably, each side chain has been found to require a minimum level of exposure before it will be oxidized under the mild conditions employed here. By considering this minimal exposure requirement, with the known sidechain reactivities, potential reporter groups may be identified. Knowledge of the expected reporter groups can be used to provide an estimate of the expected 
surface oxidation levels and is therefore of significance to the study of protein-protein and protein-ligand interactions. Although not all amino acid side chains react under the conditions presented here, the level of surface coverage, in terms of those residues that were exposed to solvent and that were not inert to oxidation, was $\sim 70 \%$. This level of coverage is far greater than would be achieved using traditional chemical derivatization methods, such as biotinylation or acetylation, wherein only a few residues can act as reporter groups. Equally significant to good coverage is the ability to quantify the level of oxidation and relate that directly to per-residue $<$ SASA $>$ values. This ability significantly elevates the level of footprint resolution, which is key to the practical application of this method in characterizing protein complexes. Such quantification facilitates the identification of occluded surfaces and should provide a powerful tool for determining the $3 \mathrm{D}$ structures of complexes that are not amenable to analysis by traditional experimental structural methods.

Recent studies have employed oxidative footprinting data to guide computational molecular docking, however, it was concluded that footprinting data alone was insufficient to provide a definitive choice of model [70]. It is anticipated that the quantitative relationships derived here to relate oxidation levels to $3 \mathrm{D}$ structure will be valuable in such approaches. Additionally, we have demonstrated that given an accurate structure for the complex, it is possible to use $<$ SASA $>$ values to predict oxidation levels that are in good agreement with experimental data. Thus, data from oxidative footprinting are likely to be particularly useful in validating independently generated molecular complexes by, for example, automated docking procedures.

\section{Acknowledgments}

The authors thank the National Institutes of Health (RR05357 and GM55230) for financial support. They also thank M. A. Duncan (UGA) for providing access to the excimer laser, and T. Cheng (UGA) for helping with its set-up. R.J.W. thanks M. R. Chance (Case Western) for useful discussions.

\section{References}

1. Englander, J. J.; Del Mar, C.; Li, W.; Englander, S. W.; Kim, J. S.; Stranz, D. D.; Hamuro, Y.; Woods, V. L. J. Protein Structure. Change Studied by Hydrogen-Deuterium Exchange, Functional Labeling, and Mass Spectrometry. Proc. Natl. Acad. Sci. U.S.A. 2003, 100, 7057-7062.

2. King, D.; Bergmann, C.; Orlando, R.; Benen, J. A.; Kester, H. C.; Visser, J. Use of Amide Exchange Mass Spectrometry to Study Conformational Changes Within the Endopolygalacturonase II-HomogalacturonanPolygalacturonase Inhibiting Protein System. Biochemistry 2002, 41, 10225-10233.

3. King, D.; Lumpkin, M.; Bergmann, C.; Orlando, R. Studying ProteinCarbohydrate Interactions by Amide Hydrogen/Deuterium Exchange Mass Spectrometry. Rapid Commun. Mass Spectrom. 2002, 16, 1569-1574.

4. Woods, V. L. Jr.; Hamuro, Y. High Resolution, High-Throughput Amide Deuterium Exchange-Mass Spectrometry (DXMS) Determination of Protein Binding Site Structure and Dynamics: Utility in Pharmaceutical Design. J. Cell. Biochem. 2001, 37(Suppl.), 89-98.

5. Zheng, X.; Wintrode, P. L.; Chance, M. R. Complementary Structural Mass Spectrometry Techniques Reveal Local Dynamics in Functionally Important Regions of a Metastable Serpin. Structure 2008, 16(1), 38-51.

6. Seyfried, N. T.; Atwood, J. A., III.; Almond, A.; Day, A. J.; Orlando, R.; Woods, R. J. Fourier Transform Mass Spectrometry to Monitor
Hyaluronan-Protein Interactions: Use of Hydrogen/Deuterium Amide Exchange. Rapid Commun. Mass Spectrom. 2007, 21, 121-131.

7. Baker, D. L.; Seyfried, N. T.; Li, H.; Orlando, R.; Terns, R. M.; Terns, M. P. Determination of Protein-RNA Interaction Sites in the Cbf5-H/ ACA Guide RNA Complex by Mass Spectrometric Protein Footprinting. Biochemistry 2008, 47(6), 1500-1510.

8. Shell, S. M.; Hess, S.; Kvaratskhelia, M.; Zou, Y. Mass Spectrometric Identification of Lysines Involved in the Interaction of Human Replication Protein a with Single-Stranded DNA. Biochemistry 2005, 44(3), 971-978.

9. Chen, H.; Schuster, M. C.; Sfyroera, G.; Geisbrecht, B. V.; Lambris, J. D. Solution Insights into the Structure of the Efb/C3 Complement Inhibitory Complex as Revealed by Lysine Acetylation and Mass Spectrometry. J. Am. Soc. Mass Spectrom. 2008, 19(1), 55-65.

10. Shkriabai, N.; Patil, S. S.; Hess, S.; Budihas, S. R.; Craigie, R.; Burke, T. R.; Le Grice, S. F. J.; Kvaratskhelia, M. Identification of an InhibitorBinding Site to HIV-1 Integrase with Affinity Acetylation and Mass Spectrometry. Proc. Nat. Acad. Sci. U.S.A. 2004, 101(18), 6894-6899.

11. Takamoto, K.; Chance, M. R. Radiolytic Protein. Footprinting with Mass Spectrometry to Probe the Structure of Macromolecular Complexes. Annu. Rev. Biophys. Biomol. Struct. 2006, 35, 251-276.

12. Maleknia, S. D.; Wong, J. W.; Downard, K. M. Photochemical and Electrophysical Production of Radicals on Millisecond Timescales to Probe the Structure, Dynamics, and Interactions of Proteins. Photochem. Photobiol. Sci. 2004, 3(8), 741-748.

13. Sharp, J. S.; Guo, J.-T.; Uchiki, T.; Xu, Y.; Dealwis, C.; Hettich, R. L. Photochemical Surface Mapping of C14S-Sm11p for Constrained Computational Modeling of Protein Structure. Anal. Biochem. 2005, 340, 201-212.

14. Xu, G.; Chance, M. R. Radiolytic Modification of Sulfur-Containing Amino Acid Residues in Model Peptides: Fundamental Studies for Protein Footprinting. Anal. Chem. 2005, 77, 2437-2449.

15. Xu, G.; Takamoto, K.; Chance, M. R. Radiolytic Modification of Basic Amino Acid Residues in Peptides: Probes for Examining ProteinProtein Interactions. Anal. Chem. 2003, 75, 6995-7007.

16. Guan, J.-Q.; Vorobiev, S.; Almo, S. C.; Chance, M. R. Mapping the G-Actin Binding Surface of Cofilin Using Synchrotron Protein Footprinting. Biochemistry 2002, 41, 5765-5775.

17. Maleknia, S. D.; Brenowitz, M.; Chance, M. R. Millisecond Radiolytic Modification of Peptides by Synchrotron X-rays Identified by Mass Spectrometry. Anal. Chem. 1999, 71, 3965-3973.

18. Aye, T. T.; Low, T. Y.; Sze, S. K. Nanosecond Laser-Induced Photochemical Oxidation Method for Protein Surface Mapping with Mass Spectrometry. Anal. Chem. 2005, 77, 5814-5822.

19. Hambly, D. M.; Gross, M. L. Laser Flash Photolysis of Hydrogen Peroxide to Oxidize Protein Solvent-Accessible Residues on the Microsecond Timescale. J. Am. Soc. Mass Spectrom. 2005, 16, 2057-2063.

20. Hambly, D.: Gross, M. Laser Flash Photochemical Oxidation to Locate Heme Binding and Conformational Changes in Myoglobin. Int. J. Mass Spectrom. 2007, 259(1/3), 124-129.

21. Sharp, J. S.; Becker, J. M.; Hettich, R. L. Analysis of Protein Solvent Accessible Surfaces by Photochemical Oxidation and Mass Spectrometry. Anal. Biochem. 2004, 76, 672-683.

22. Sharp, J. S.; Tomer, K. B. Analysis of the Oxidative Damage-Induced Conformational Changes of apo- and holo-Calmodulin by DoseDependent Protein Oxidative Surface Mapping. Biophys. J. 2007, 92(5), 1682-1692.

23. Platis, I. E.; Ermacora, M. R.; Fox, R. O. Oxidative Polypeptide Cleavage Mediated by EDTA-Fe Covalently Linked to Cysteine Residues. Biochemistry 1993, 32(47), 12761-12767.

24. Brenowitz, M. R.; Chance, M.; Dhavan, G.; Takamoto, K. Probing the Structural Dynamics of Nucleic Acids by Quantitative Time-Resolved and Equilibrium Hydroxyl Radical "footprinting". Curr. Opin. Struct. Biol. 2002, 12(5), 648-653.

25. Greiner, D. P.; Hughes, K. A.; Meares, C. F. Radiolytic Protein Surface Mapping. Biochem. Biophys. Res. Commun. 1996, 225(3), 1006-1008.

26. Maleknia, S. D.; Chance, M. R.; Downard, K. M. Electrospray-Assisted Modification of Proteins: A Radical Probe of Pprotein Structure. Rapid Commun. Mass Spectrom. 1999, 13(23), 2352-2358.

27. Wong, J. W.; Maleknia, S. D.; Downard, K. M. Hydroxyl Radical Probe of the Calmodulin-Melittin Complex Interface by Eelectrospray Ionization Mass Spectrometry. J. Am. Soc. Mass Spectrom. 2005, 16(2), 225-233.

28. Berens, C.; Streicher, B.; Schroeder, R.; Hillen, W. Visualizing Metal-Ion Binding Sites in Group I Introns by Iron(II)-Mediated Fenton Reactions. Chem. Biol. 1998, 5(3), 163-175.

29. Hampel, K. J.; Burke, J. M. Time-Resolved Hydroxyl-Radical Footprinting of RNA Using Fe(II)-EDTA. Methods 2001, 23(3), 233-239.

30. Tullius, T. D.; Dombroski, B. A. Hydroxyl Radical "footprinting": High-Resolution Information About DNA-Protein Contacts and Application to $\lambda$ Repressor and Cro Protein. Proc. Nat. Acad. Sci. U.S.A. 1986, 83(15), 5469-5473.

31. Heyduk, E.; Heyduk, T. Mapping Protein Domains Involved in Macromolecular Interactions: A Novel Protein Footprinting Approach. Biochemistry 1994, 33(32), 9643-9650.

32. Sharp, J. S.; Becker, J. M.; Hettich, R. L. Protein Surface Mapping by Chemical Oxidation: Structural Analysis by Mass Spectrometry. Analyt. Biochem. 2003, 313, 216-225.

33. Garrison, W. M. Reaction Mechanisms in the Radiolysis of Peptides and Proteins. Chem. Rev. 1987, 87, 381-398. 
34. Eng, J. K.; McCormack, A. L.; Yates, J. R. An Approach to Correlate Tandem Mass Spectral Data of Peptides with Amino Acid Sequences in a Protein Database. J. Am. Soc. Mass Spectrom. 1994, 5(11), 976-989.

35. Perkins, D. N.; Pappin, D. J.; Creasy, D. M.; Cottrell, J. S. ProbabilityBased Protein Identification by Searching Sequence Databases Using Mass Spectrometry Data. Electrophoresis 1999, 20(18), 3551-3567.

36. Bern, M.; Cai, Y.; Goldberg, D. Lookup Peaks: A Hybrid of de Novo Sequencing and Database Search for Protein Identification by Tandem Mass Spectrometry. Anal. Chem. 2007, 79(4), 1393-1400.

37. Mueller, L. N.; Brusniak, M. Y.; Mani, D. R.; Aebersold, R. An Assessment of Software Solutions for the Analysis of Mass Spectrometry Based Quantitative Proteomics Data. I. Proteome Res. 2008, 7(1), 51-61.

38. Barondes, S. H.; Cooper, D. N. W.; Gitt, M. A.; Leffler, H. Galectins, Structure and Function of a Large Family of Animal Lectins. J. Biol. Chem. 1994, 269, 20907-20810.

39. Cho, M.; Cummings, R. D. Galectin-1, a $\beta$-Galactoside-Binding Lectin in Chinese Hamster Ovary Cells. I. Physical and Chemical Characterization. J. Biol. Chem. 1995, 270(10), 5198-5206.

40. Hirabayashi, J.; Kasai, K. Effect of Amino Acid Substitution by SiteDirected Mutagenesis on the Carbohydrate Recognition and Stability of Human 14-kDa $\beta$-Galactoside-Binding Lectin. J. Biol. Chem. 1991, 266(35), 23648-23653.

41. Kasai, K.; Hirabayashi, J. Galectins: A Family of Animal Lectins that Decipher Glycocodes. J. Biochem. 1996, 119(1), 1-8.

42. Stillman, B. N.; Hsu, D. K.; Brewer, C. F.; Johnson, P.; Liu, F. T.; Baum, L. G. Galectin-3 and Galectin-1 Bind Distinct Cell Surface Glycoprotein Receptors to Induce T Cell Death. J. Immunol. 2006, 176, 778-789.

43. Fitzner, B.; Walzel, H.; Sparmann, G.; Emmrich, J.; Liebe, S.; Jaster, R. Galectin-1 is an Inductor of Pancreatic Stellate Cell Activation. Cell. Signal. 2005, 17(10), 1240-1247.

44. Liu, F. T. Galectins: A New Family of Regulators of Inflammation. Clin. Immunol. 2000, 97(2), 79-88.

45. Walzel, H.; Blach, M.; Hirabayashi, J.; Arata, Y.; Kasai, K.-I., Brock, J. Galectin-Induced Activation of the Transcription Factors NFAT and AP-1 in Human Jurkat T-Lymphocytes. Cell. Signal. 2002, 14(10), 861868 .

46. Wang, J. L.; Gray, R. M.; Haudek, K. C.; Patterson, R. J. Nucleocytoplasmic Lectins. Biochem. Biophys. Acta 2004, 1673(1/2), 75-93.

47. Dyekjaer, J. D.; Woods, R. J. In NMR Spectroscopy and Computer Modeling of Carbohydrates. Recent Advances, Vol. CMXXX, Vliegenthart, J. F. G., Woods, R. J., Eds.; American Chemical Society: Washington, 2006; p. 18.

48. Cozzetto, D.; Tramontano, A. Relationship Between Multiple Sequence Alignments and Quality of Protein Comparative Models. Proteins 2005, 58(1), 151-157.

49. Fernandez-Fuentes, N.; Rai, B. K.; Madrid-Aliste, C. J.; Fajardo, J. E.; Fiser, A. Comparative Protein Structure Modeling by Combining Multiple Templates and Optimizing Sequence-to-Structure Alignments. Bioinformatics 2007, 23(19), 2558-2565.

50. Ginalski, K. Comparative Modeling for Protein Structure Prediction. Curr. Opin. Struct. Biol. 2006, 16(2), 172-177.

51. Fouillit, M.; Levi-Strauss, M.; Giudicelli, V.; Lutomski, D.; Bladier, D.; Caron, M.; Joubert-Caron, R. Affinity Purification and Characterization of Recombinant Human Galectin-1. J. Chromatogr. B 1998, 706(1), 167171.

52. Schagger, H.; von Jagow, G. Tricine-Sodium Dodecyl SulfatePolyacrylamide Gel Electrophoresis for the Separation of Proteins in the Range from 1 to $100 \mathrm{kDa}$. Anal. Biochem. 1987, 166(2), 368-379.

53. Pedrioli, P. G. A.; Eng, J. K.; Hubley, R.; Vogelzang, M.; Deutsch, E. W.; Raught, B.; Pratt, B.; Nilsson, E.; Angeletti, R. H.; Apweiler, R.; Cheung, K.; Costello, C. E.; Hermjakob, H.; Huang, S.; Julian, R. K.; Kapp, E.; McComb, M. E.; Oliver, S. G.; Omenn, G.; Paton, N. W.; Simpson, R.;
Smith, R.; Taylor, C. F.; Zhu, W. M.; Aebersold, R. A Common Open Representation of Mass Spectrometry Data and Its Application to Proteomics Research. Nat. Biotechnol. 2004, 22(11), 1459-1466.

54. Tabb, D. L.; Fernando, C. G.; Chambers, M. C. MyriMatch: Highly Accurate Tandem Mass Spectral Peptide Identification by Multivariate Hypergeometric Analysis. J. Proteome Res. 2007, 6(2), 654-661.

55. Guan, J.-Q.; Chance, M. R. Structural Proteomics of Macromolecular Assemblies Using Oxidative Footprinting and Mass Spectrometry. Trends Biochem. Sci. 2005, 30, 583-592.

56. Xu, G.; Chance, M. R. Radiolytic Modification and Reactivity of Amino Acid Residues Serving as Structural Probes for Protein Footprinting. Anal. Chem. 2005, 77, 4549-4555.

57. Berlett, B. S.; Stadtman, E. R. Protein Oxidation in Aging, Disease, and Oxidative Stress. J. Biol. Chem. 1997, 272(33), 20313-20316.

58. Kubota, K.; Yoneyama-Takazawa, T.; Ichikawa, K. Determination of Sites citrullinated by Peptidylarginine Deiminase Using $18 \mathrm{O}$ Stable Isotope Labeling and Mass Spectrometry. Rapid Commun. Mass Spectrom. 2005, 19(5), 683-688.

59. Boja, E. S.; Fales, H. M. Overalkylation of a Protein Digest with Iodoacetamide. Anal. Chem. 2001, 73(15), 3576-3582.

60. Lopez-Lucendo, M. F.; Solis, D.; Andre, S.; Hirabayashi, J.; Kasai, K. Kaltner, H.; Gabius, H. J.; Romero, A. Growth-Regulatory Human Galectin-1: Crystallographic Characterization of the Structural Changes Induced by Single-Site Mutations and Their Impact on the Thermodynamics of Ligand Binding. J. Mol. Biol. 2004, 343, 957-970.

61. Berman, H. M.; Battistuz, T.; Bhat, T. N.; Bluhm, W. F.; Bourne, P. E.; Burkhardt, K.; Feng, Z.; Gilliland, G. L.; Iype, L.; Jain, S.; Fagan, P.; Marvin, J.; Padilla, D.; Ravichandran, V.; Schneider, B.; Thanki, N.; Weissig, H.; Westbrook, J. D.; Zardecki, C. The Protein Data Bank. Acta Crystallogr. D 2002, 58(Pt 6 No. 1), 899-907.

62. Case, D. A.; Darden, T. A.; Cheatham, T. E. III; Simmerling, C. L.; Wang J.; Duke, R. E.; Luo, R.; Merz, K. M.; Pearlman, D. A.; Crowley, M.; Walker, R. C.; Zhang, W.; Wang, B.; Hayik, S.; Roitberg, A.; Seabra, G.; Wong, K. F.; Paesani, F.; Wu, X.; Brozell, S.; Tsui, V.; Gohlke, H.; Yang, L.; Tan, C.; Mongan, J.; Hornak, V.; Cui, G.; Beroza, P.; Mathews, D. H.; Schafmeister, C.; Ross, W. S.; Kollman, P. A. AMBER 9, University of California: San Francisco, 2006.

63. Wang, J.; Cieplak, P.; Kollman, P. A. How Well Does a Restrained Electrostatic Potential (RESP) Model Perform in Calculating Conformational Energies of Organic and Biological Molecules? J. Comput. Chem. 2000, 21(12), 1049-1074.

64. Jorgensen, W. L.; Chandrasekhar, J.; Madura, J. D.; Impey, R. W.; Klein, M. L. Comparison of Simple Potential Functions for Simulating Liquid Water. J. Phys. Chem. 1983, 79, 926-935.

65. Hubbard, S. J.; Thornton, J. M. NACCESS, 2.1.1; University College London: London, 1993

66. Sullards, M. C.; Reiter, J. A. Primary and Secondary Locations of Charge Sites in Angiotensin II $(\mathrm{M}+2 \mathrm{H})(2+)$ Ions Formed by Electrospray Ionization. J. Am. Soc. Mass Spectrom. 2000, 11(1), 40-53.

67. Bull, H. B.; Breese, K. Surface-Tension of Amino-Acid SolutionsHydrophobicity Scale of Amino-Acid Residues. Arch. Biochem. Biophys. 1974, 161(2), 665-670.

68. Zhou, S. L.; Cook, K. D. A Mechanistic Study of Electrospray Mass Spectrometry: Charge Gradients Within Electrospray Droplets and Their Influence on Ion Response. J. Am. Soc. Mass Spectrom. 2001, 12(2), 206-214.

69. Sharp, J. S.; Tomer, K. B. Effects of Anion Proximity in Peptide Primary Sequence on the Rate and Mechanism of Leucine Oxidation. Anal. Chem. 2006, 78(14), 4885-4893.

70. Kamal, J. K.; Chance, M. R. Modeling of Protein Binary Complexes Using Structural Mass Spectrometry Data. Protein Sci. 2007, 17, 1-16. 